\title{
Effects of Cold Rolling and Aging Treatment on the Properties of $\mathrm{Cu}-\mathrm{Be}$ Alloy
}

\author{
Masoud Ibrahim Mohamed \\ Chemical and Materials Engineering Department, Northern Border University, Arar, Saudi Arabia, \\ On leave from Mechanical Engineering Department, Fayoum University, Egypt \\ ibrahim_64@yahoo.com
}

\begin{abstract}
The effects of precipitated phases during aging treatment on the properties of the $\mathrm{Cu}$-Be alloy have been extensively studied. In this study, the effect of cold rolling on the precipitated phases of the $\mathrm{Cu}-\mathrm{Be}$ alloy compared with nondeformed alloy during isothermal and low heating rate aging of $\mathbf{2}^{\mathbf{0}} \mathrm{C} / \mathbf{m i n}$ have been investigated. Hardness changes, differential scanning calorimetry (DSC), dilatation analysis, and transmission electron microscopy (TEM) were used in this study. Hardening and contraction were strongly increased at an early aging time for the cold rolled $\mathrm{Cu}-\mathrm{Be}$ alloy. In addition, the DSC curves revealed an exothermic peak from the $\gamma^{\prime \prime}$ phase. This peak increased and shifted to lower aging time by increasing the cold rolling reduction. In addition, the hardness remarkably increased at lower aging temperatures for the cold rolled specimens. The contraction from the dilatation curves and the exothermic peaks shifted to lower aging temperatures in cold rolled specimens. The hardening of $\mathrm{Cu}-\mathrm{Be}$ alloy is believed to be from the $\gamma^{\prime}$ phase, and the contraction and the first exothermic peak in DSC curves from $\gamma^{\prime \prime}$ phase. TEM observations are in a good agreement with the above explanation and strongly revealed that $\gamma^{\prime \prime}$ and $\gamma^{\prime}$ phases were highly accelerated by the effect of cold rolling.
\end{abstract}

Keywords-precipitation hardening; transmission electron microscopy;- age hardening; solution treatment; cold rolling

\section{INTRODUCTION}

$\mathrm{Cu}-\mathrm{Be}$ alloy has been used very widely for springs, diaphragms, bearings and non-sparking tools because it has excellent mechanical properties, high electrical conductivity, and high corrosion resistance. Aging after quenching from solution treatment remarkably hardens the alloy [1-4]. The precipitation sequence in this alloy has been extensively studied and can be summarized as follows [5-8]: $\alpha$ supersaturated solid-solution $\rightarrow$ G.P zones $\rightarrow \gamma^{\prime \prime} \rightarrow \gamma^{\prime} \rightarrow \gamma(\mathrm{Cu}-$ Be). The G.P zones are monolayer plates that form coherently on $\{100\}$ matrix and revealed as streaks along $\langle 200\rangle \alpha$ directions, $\gamma^{\prime \prime}$ is a metastable phase with a monoclinic structure appearing as intensity maxima in the streaks along the $\langle 200\rangle \alpha$ directions with aging treatment [9-13]. With farther aging the intensity maxima began to change to arrowhead-like shape, which shows the precipitation of $\gamma^{\prime}$ phase, this phase is metastable with a b.c.c. structure. The stable $\gamma$ phase precipitate has an equilibrium b.c.c. structure [8, 14-19]. Few studies have been done on the effect of cold rolling on the hardening behavior of $\mathrm{Cu}-\mathrm{Be}$ alloy. In this paper the precipitation of $\gamma^{\prime \prime}$ and $\gamma^{\prime}$ phases through aging of this alloy under the effect of cold rolling have been studied using hardness measurements, thermo-mechanical analysis (TMA), and differential scanning calorimetry (DSC). Transmission electron microscopy (TEM) has been used for phase transformation studies.

\section{EXPERIMENTAL METHOD}

Cold-rolled plates of $\mathrm{Cu}-\mathrm{Be}$ alloy (Japanese Industrial Standard \#C1720), which contains beryllium of $1.9 \mathrm{mass} \%$ and $0.2 \mathrm{mass} \%$ cobalt were used in this study. This alloy was received as a cold rolled plate of $2.5 \mathrm{~mm}$ thickness. Test pieces with size of $10 \mathrm{~mm}$ width, $120 \mathrm{~mm}$ length were cut out from the $2.5 \mathrm{~mm}$ thickness plate in the rolling direction Figure 1(a).

(a)
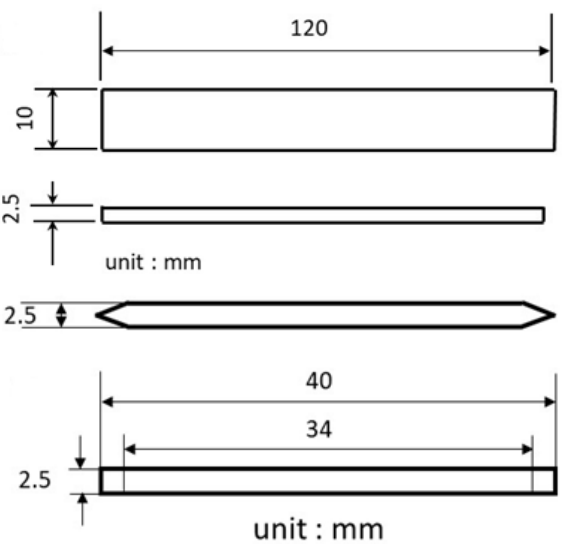

(i) $80^{\circ} \mathrm{C} \times 2 \mathrm{~h}$

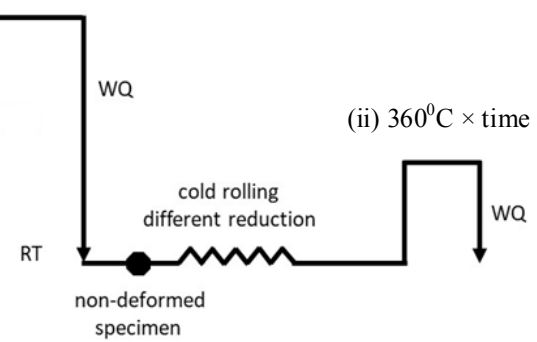

Fig. 1. (a) Specimen for cold rolling, (b) Specimen for dilatation measurements, and (c) Illustration of the heat treatments for the ND and the CR specimens: (i) solution treatment, (ii) isothermal aging at $360^{\circ} \mathrm{C}$. 
The cutout test pieces were first solution heat-treated at $800^{\circ} \mathrm{C}$ for 2 hours followed by water quenching. The quenched specimens were cold rolled (at room temperature) with different reduction ratios $(1,2,4,8$ and $12 \%)$. These cold rolled specimens were aged treated at $360^{\circ} \mathrm{C}$ for different time intervals up to $180 \mathrm{~min}$. Figure 1 (c) shows the heat treatment cycle. Specimens of $10 \mathrm{~mm} \times 10 \mathrm{~mm} \times 2.5 \mathrm{~mm}$ were cut out from the non-deformed (ND) and cold rolled (CR) plates for hardness measurements after aging at $360^{\circ} \mathrm{C}$. Hardness was measured by the mean value of 10 measurements using Vickers hardness tester with the load of $9.8 \mathrm{~N}$. Specimens of $2.5 \mathrm{~mm} \times 2.5 \mathrm{~mm} \times 40 \mathrm{~mm}$ were cut out from the aged plates for dilatation measurements through heating of $\mathrm{Cu}-\mathrm{Be}$ alloy (Figure 1(b)). Specimens of $20 \mathrm{mg}$ in weight were used for DSC tests. Specimens of $2.5 \mathrm{~mm}$ width, $13 \mathrm{~mm}$ length were cut out for the TMA during heating at $800^{\circ} \mathrm{C}$. Thin foils suitable for TEM observation were prepared using double jet electro polishing technique. Diffraction pattern, bright-field image were performed, the diffraction pattern was obtained on the [001] direction. The transmission electron microscope employed was Hitachi H-9000NAR.

\section{RESULTS AND DISCUSSION}

Hardness changes for the ND and CR plates during aging at $360^{\circ} \mathrm{C}$ are shown in Figure 2. The $\mathrm{Cu}-\mathrm{Be}$ alloy shows higher hardness values compared with the non-deformed.

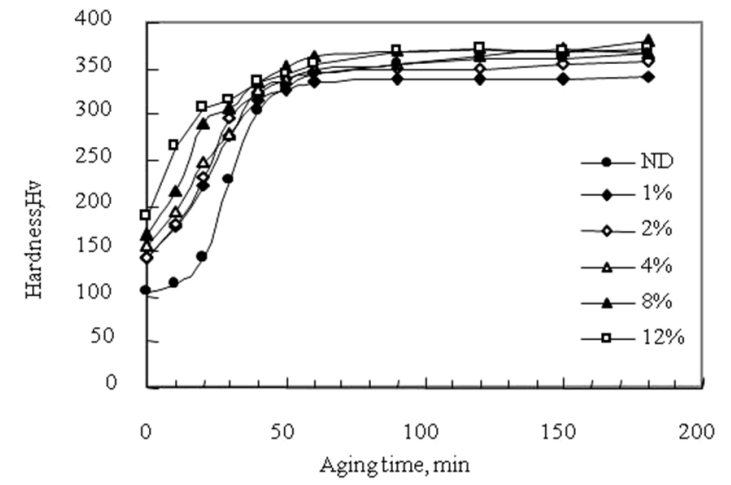

Fig. 2. Changes in hardness of $\mathrm{Cu}-\mathrm{Be}$ alloy during isothermal aging at $360^{\circ} \mathrm{C}$

A little cold rolling enhances the hardness remarkably at an early stage of aging and the hardness increases slightly with increasing reduction ratio of cold rolling. It is clear that the hardness of the CR specimens increases earlier than the one of the ND specimen. After 20min aging, the hardness increased from about $150 \mathrm{Hv}$ to $220 \mathrm{Hv}$ and $310 \mathrm{Hv}$ at $1 \%$ and $12 \%$ for $\mathrm{ND}$ and CR, respectively. Thus, it seems that cold rolling promotes the hardening of this alloy at early aging time. Dilatation tests revealed higher shrinkage at early aging time after cold rolling as shown in Figure 3. It is clear from Figures 2 and 3 that the hardening and dilatation curves of the CR and ND specimens are strongly coexisting, showing remarkable increase of the hardness and shrinkage at early aging stage and are almost steady after about one hour aging. Previous studies on the effect of cooling rate on aging behavior of $\mathrm{Cu}-\mathrm{Be}$ alloy showed that the contraction was caused by the precipitation of $\gamma^{\text {" }}$ phase while the hardening was mainly related to $\gamma^{\prime}$ phase $[8,9]$. Therefore, it can be concluded that cold rolling enhanced the precipitation of both $\gamma^{\prime \prime}$ and $\gamma^{\prime}$ phases. This will be clarified below by TEM observation for CR and ND specimens after different heat treatments.

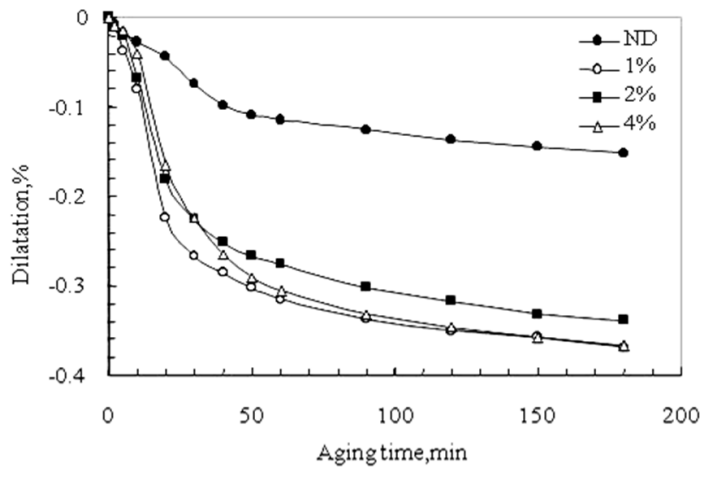

Fig. 3. Dilatation behavior of $\mathrm{Cu}-\mathrm{Be}$ alloy during isothermal aging at $360^{\circ} \mathrm{C}$

Hardness changes were measured for the ND and CR specimens (up to $30 \%$ reduction) after heating to different temperatures at a heating rate of $2^{\circ} \mathrm{C} / \mathrm{min}$, followed by water quenching. Figure 4 shows that as the heating temperature increases, the hardness increases to reach a maximum at about $380^{\circ} \mathrm{C}$ and then decreases. At $300^{\circ} \mathrm{C}$, remarkable hardness increase was revealed for the $\mathrm{CR}$ specimens compared with the ND specimens. The maximum hardness slightly increases and shifts to lower temperatures as the cold rolling reduction ratio increases. Generally, the hardness increases of $\mathrm{Cu}-\mathrm{Be}$ alloy mainly due to $\gamma^{\prime}$ phase precipitation. At higher temperatures, over $380^{\circ} \mathrm{C}$, the hardness decreased due to $\gamma^{\prime}$ phase dissolution and/or $\gamma$ stable phase formation as reported in $[8,9,12]$.

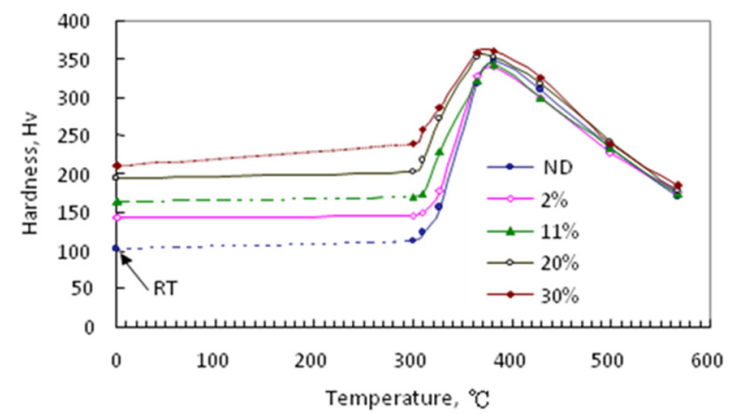

Fig. 4. Effect of cold rolling on hardening of $\mathrm{Cu}-\mathrm{Be}$ alloy, heating rate $2^{\circ} \mathrm{C} / \mathrm{min}$

Figure 5 shows the dilatation curves for the ND and CR specimens of this $\mathrm{Cu}-\mathrm{Be}$ alloy during heating up to $600^{\circ} \mathrm{C}$ at $2^{\circ} \mathrm{C} / \mathrm{min}$ heating rate. The cold rolled specimens show that shrinkage increase started at about $280^{\circ} \mathrm{C}$. With increasing temperature the shrinkage increased to a maximum of $0.20 \%$ at about $370^{\circ} \mathrm{C}$, and then decreased. As the reduction ratio of cold rolling increased, the maximum shrinkage slightly decreased and shifted to lower temperatures. 


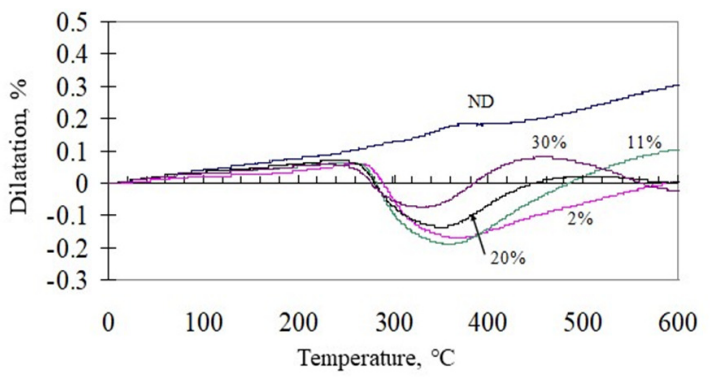

Fig. 5. Effect of cold rolling on dilatation of $\mathrm{Cu}-\mathrm{Be}$ alloy, heating rate $2^{\circ} \mathrm{C} / \mathrm{min}$

On the other hand, the ND specimens show a very slight expansion during the same heating conditions. It is interesting to note that the hardening and dilatation curves for this alloy (Figures 4 and 5) have similar behavior of increasing to maximum and decreasing as the heating temperature increases. Maximum contraction and maximum hardness are obtained at the same temperature of about $370 \sim 380^{\circ} \mathrm{C}$ and shift to lower temperatures with increasing cold rolling reduction ratio. Figure 6 shows the DSC curves for the ND and the CR specimens during heating up to $500^{\circ} \mathrm{C}$. The first exothermic peak is the highest for the ND specimen and appeared around $350^{\circ} \mathrm{C}$. This peak decreased and shifted to lower temperatures for the cold rolled specimens. With further heating a peak like a shoulder appeared at around $380^{\circ} \mathrm{C}$.

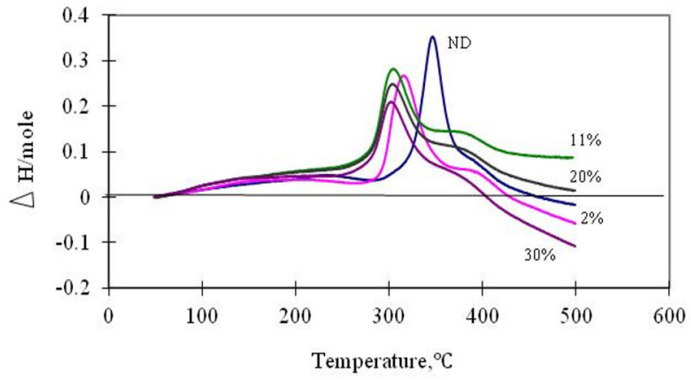

Fig. 6. DSC curves of $\mathrm{Cu}-\mathrm{Be}$ alloy, heating rate $2^{\circ} \mathrm{C} / \mathrm{min}$

The first exothermic peak may be due to the $\gamma^{\prime \prime}$ phase and/or G.P zones precipitation. On the other hand, the shoulder may be due to the $\gamma^{\prime}$ phase precipitation. This assumption is based on the maximum hardness obtained at the same temperature of $380^{\circ} \mathrm{C}$ as shown in Figure 4. TEM observation was investigated for $\mathrm{CR}$ and $\mathrm{ND} \mathrm{Cu}-\mathrm{Be}$ alloys after heat treatment at different conditions corresponds to the different exothermic heat changes, dilatation and hardness changes. If we consider the height of the peaks as an indication of the amount of the precipitated phases, it can be concluded that, cold rolling enhanced the formation of $\gamma^{\text {" }}$ phase and G.P zones and slightly decreased its amount. On the other hand, the amount of $\gamma^{\prime}$ phase increased by cold rolling. As mentioned earlier, shrinkage mainly occurs due to the precipitation of $\gamma^{\prime \prime}$ phase. From this point of view it seems that the first peak was obtained from the DSC curves of Figure 6 for the ND specimen mainly due to G.P zones formation, not $\gamma^{\prime \prime}$ phase precipitation.
Figure 7(a) and (d) shows the electron diffraction pattern of the ND and 4\% CR specimens respectively. The ND specimen showed mainly weak G.P. zones, while the $4 \%$ CR specimen revealed G.P. zones with small amount of $\gamma^{\prime \prime}$ phase (marked with arrows). The electron diffraction pattern of the ND specimen after aging at $360^{\circ} \mathrm{C}$ for $20 \mathrm{~min}$ revealed only G.P zones as shown in Figure 7(b). It is noted, however, that $4 \%$ CR specimen precipitates $\gamma^{\prime \prime}$ and $\gamma^{\prime}$ phases after the same aging conditions (Figure 7(e)). Figure 7(c) and (f) shows the electron diffraction patterns of the ND and $4 \% \mathrm{CR}$ specimens after heating to $348^{\circ} \mathrm{C}$ and $316^{\circ} \mathrm{C}$ respectively. The $\mathrm{ND}$ specimen showed G.P zones and small amount of $\gamma^{\prime \prime}$ phase, while 4\%CR specimen showed mainly $\gamma^{\prime \prime}$ phase (marked with arrows) after heating to the lower temperature of $316^{\circ} \mathrm{C}$. It is noted, however, that the 4\% CR specimen precipitates $\gamma^{\prime \prime}$ and $\gamma^{\prime}$ phases after the same aging condition (Figure 7(e)).

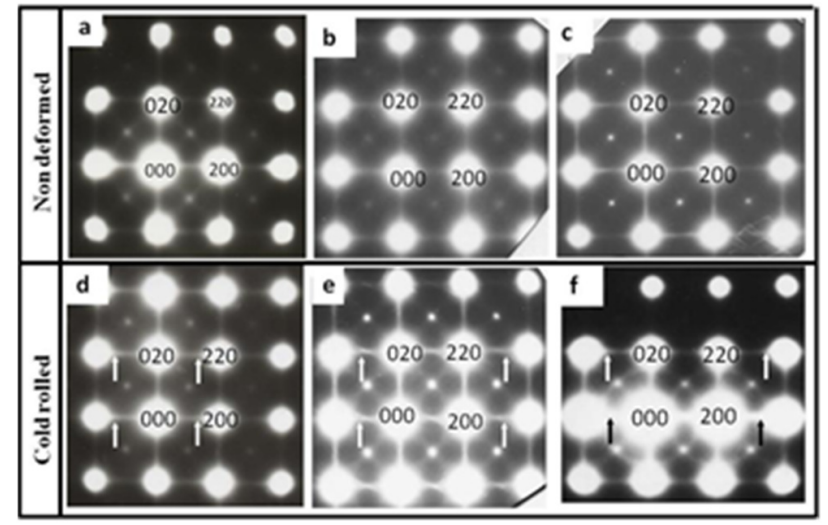

Fig. 7. TEM diffraction pattern, (a) as ST, (b) S.T $+20 \mathrm{~min}$ aging, (c) S.T $+348^{\circ} \mathrm{C}$, (d) $4 \% \mathrm{CR}$ (e), $4 \% \mathrm{CR}+20 \mathrm{~min}$ aging, and (f) $2 \% \mathrm{CR}+316^{\circ} \mathrm{C}$. Incident beam is parallel to [001]

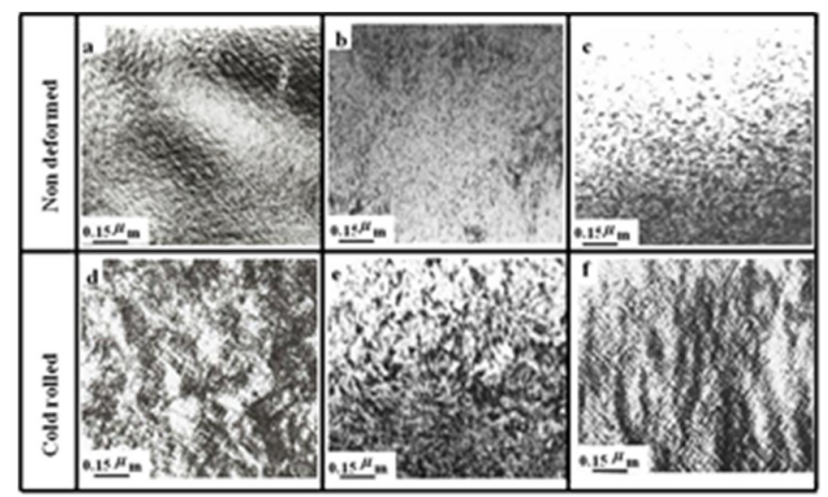

Fig. 8. TEM micrograph, shows the bright field image corresponding to Figure 7

Figure 8 shows the bright filed image (BFI) corresponding to the electron diffraction pattern in Figure 7. Electron diffraction pattern of the ND and $2 \% \mathrm{CR}$ specimens after heating to $380^{\circ} \mathrm{C}$ and $360^{\circ} \mathrm{C}$ respectively are shown in Figure 9(a) and (d). The ND specimen revealed mainly $\gamma^{\prime}$ phase as arrowhead structure at 1/3[002]. On the other hand, 2\% CR specimen showed $\gamma^{\prime}$ phase after heating to the lower temperature of $360^{\circ} \mathrm{C}$. This means that cold rolling promotes 
the precipitation of $\gamma^{\prime \prime}$ and $\gamma^{\prime}$ phases coincidently with the result of the hardness change, DSC curves, TMA curves and dilatation. Figure 9(b) and (e) shows the electron diffraction pattern for the ND and $2 \% \mathrm{CR}$ specimens after heating to $500^{\circ} \mathrm{C}$ respectively. At this high temperature mainly $\gamma$ phase was precipitated in the ND and $2 \%$ CR specimens. $\gamma$ phase was revealed more clearly in $2 \% \mathrm{CR}$ specimen. In Figures $9(\mathrm{c})$ and (f) the schematics for the electron diffraction pattern are shown. Thus, phase precipitation depends strongly on cold rolling, it is apparent that the precipitation of $\gamma^{\prime \prime}$ and $\gamma^{\prime}$ phases was accelerated by the effect of cold rolling.

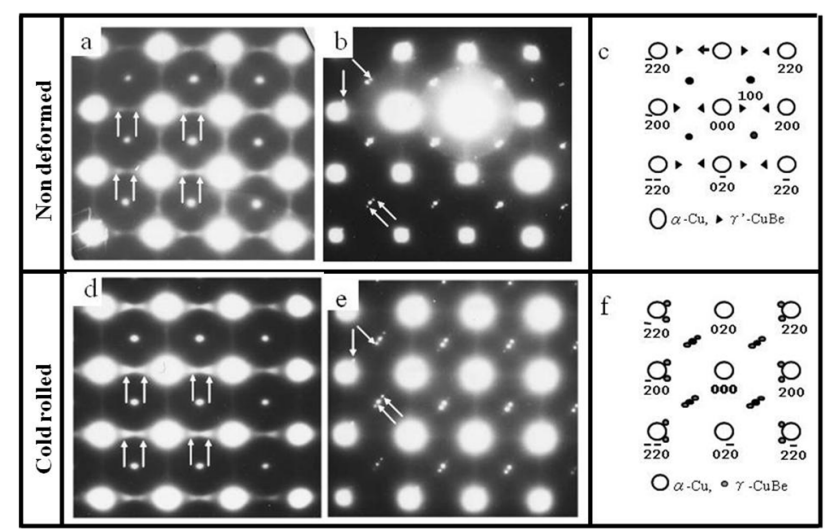

Fig. 9. Electron diffraction pattern: (a) $\mathrm{ST}+380^{\circ} \mathrm{C}$, (b) $\mathrm{ST}+500^{\circ} \mathrm{C}$, (c) schematic illustration for the diffraction pattern, (d) $2 \% \mathrm{CR}+360^{\circ} \mathrm{C}$, (e) $2 \%$ $\mathrm{CR}+500^{\circ} \mathrm{C}$, (f) schematic illustration for the diffraction pattern. The incident beam is parallel to [001].

\section{CONCLUSION}

The influences of cold rolling and heat treatment on the age-hardening behavior of the $\mathrm{Cu}-\mathrm{Be}$ alloy were investigated for ND and CR specimens. The obtained results are summarized as follows:

- At early stage aging, the hardening and shrinkage of the $\mathrm{Cu}-\mathrm{Be}$ alloy were strongly suppressed by the effect of cold rolling. Maximum hardness and shrinkage appeared at almost the same temperature of about $370-380^{\circ} \mathrm{C}$.

- DSC curves showed that cold rolling promotes the first exothermic peak and shifts it to lower temperatures, thus cold rolling enhanced the precipitation of $\gamma^{\prime \prime}$ phase.

- The TMA curves revealed that cold rolled specimens highly shrink with heating and the maximum shrinkage shifts to lower temperature with increasing of the cold rolling reduction.

- DSC, dilatation changes, TMA, and TEM studies coexisted and revealed that the precipitation of $\gamma^{\prime \prime}$ and $\gamma^{\prime}$ phases were accelerated by cold rolling.

\section{ACKNOWLEDGEMENT}

The author wishes to acknowledge the approval and the support of this research study by the grant no. 7593-ENG2018-3-9-F from the Deanship of Scientific Research, Northern Border University, Arar, Saudi Arabia.

\section{REFERENCES}

[1] E. Rocha-Rangel, J. A. Rodrguez-Garcia, C. A. Hernandez-Bocanegra, "Precipitation hardening of Cu-Be alloys", ChemXpress Vol. 5 No. 4, pp. 132-136, 2014

[2] M. Mankani, S. S. Sharma, "Heat treatment of mill-hardened beryllium copper for space applications", Universal Journal of Mechanical Engineering, Vol. 3, No. 4, pp. 147-150, 2015

[3] Z. Zhu, Y. Cai, K. Song, Y. Zhou, J. Zou, "Precipitation Characteristics of the Metastable $\gamma^{\prime \prime}$ Phase in a Cu-Ni-Be Alloy", Materials, Vol. 11, No. 8, Article ID 1394, 2018

[4] T. Tang, Y. L. Kang, L. J. Yue, X. L. Jiao, "Precipitation behavior of $\mathrm{Cu}-1.9 \mathrm{Be}-0.3 \mathrm{Ni}-0.15 \mathrm{Co}$ alloy during aging", Acta Metallurgica Sinica (English Letters), Vol. 28, No. 3, pp. 307-315, 2015

[5] Y. Tang, Y. Kang, L. Yue, X. Jiao, "Mechanical properties optimization of a $\mathrm{Cu}-\mathrm{Be}-\mathrm{Co}-\mathrm{Ni}$ alloy by precipitation design", Journal of Alloys and Compounds, Vol. 695, pp. 613-625, 2017

[6] Y. Tang, Y. Kang, L. Dejia, M. Shen, Y. Hu, L. Zhao, "Tuning Low Cycle Fatigue Properties of $\mathrm{Cu}-\mathrm{Be}-\mathrm{Co}-\mathrm{Ni}$ Alloy by Precipitation Design", Metals-Open Access Metallurgy Journal, Vol. 8, Article ID 444,2018

[7] S. Montecinos, S. Tognana, W. Salgueiro, "Influence of microstructure on the Young's modulus in a Cu-2Be (wt.\%) alloy", Journal of Alloys and Compounds, Vol. 729, pp. 43-48, 2017

[8] L. Yagmur, O. Duygulu, B. Aydemir, "Investigation of metastable $\gamma^{\prime}$ precipitate using HRTEM in aged $\mathrm{Cu}-\mathrm{Be}$ alloy", Materials Science and Engineering A, Vol. 528, No. 12, pp. 4147-4151, 2011

[9] W. Bonfield, B. C. Edwards, "Precipitation hardening in $\mathrm{Cu} 1.81$ wt \% Be 0.28 wt \% Co", Journal of Materials Science, Vol. 9, No. 3, pp. 398408, 1974

[10] I. M. Masoud, K. Naito, H. Era, K. Kishitake, "A Shape Memory Behavior Newely Reveled in Cu-Be Alloy", 7th Cairo University International MDP Conference, Cairo, Egypt, February 15-17, 2000

[11] L. Yang, F. Y. Zhang, M. F. Yan, M. L. Zhang, "Microstructure and mechanical properties of multiphase layer formed during thermodiffusing of titanium into the surface of C17200 copper-beryllium alloy”, Applied Surface Science, Vol. 292, No. 1, pp. 225-230, 2014

[12] K. Esmati, H. Omidvar, J. Jelokhani, M. Naderi, "Study on the microstructure and mechanical properties of diffusion brazing joint of C17200 copper beryllium alloy“", Materials \& Design, Vol. 53, pp. 766773,2014

[13] A. Khodabakhshi, V. Abouei, N. Mortazavi, S. H. Razavi, H. Hooshyar, M. Esmaily, "Effects of cold working and heat treatment on microstructure and wear behaviour of $\mathrm{Cu}-\mathrm{Be}$ alloy $\mathrm{C} 1720$ ", TribologyMaterials, Surfaces \& Interfaces, Vol. 9, No. 3, pp. 118-127, 2015

[14] R. Monzen, S. Okawara, C. Watanable, "Stress-assisted nucleation and growth of $\gamma^{\prime \prime}$ and $\gamma^{\prime}$ precipitates in a $\mathrm{Cu}-1.2 \mathrm{wt} \% \mathrm{Be}-0.1 \mathrm{wt} \% \mathrm{Co}$ alloy aged at $320^{\circ} \mathrm{C} "$, Philosophical Magazine, Vol. 92, No. 14, pp. 18261843,2012

[15] R. J. Price, A. Kelly, "Deformation of age hardened crystals of copper1.8 wt.\% beryllium", Acta Metallurgica, Vol. 11, No. 8, pp. 915-922, 1963

[16] W. Ozgowicz, E. Kalinowska-Ozgowicz, B. Grzegorczyk, "Thermomechanical treatment of low-alloy copper alloys of the kind $\mathrm{CuCo} 2 \mathrm{Be}$ and CuCo1NiBe", Journal of Achevements in Materials and Manfacturing Engineering, Vol. 46, No. 2, pp. 161-168, 2011

[17] R. O. Galicia, C. G. Garcia, M. A. Alcantara, A. H. Vazquez, "Influence of Heat Treatment and Composition Variations on Microstructure, Hardness, and Wear Resistance of C18000 Copper Alloy", ISRN Mechanical Engineering, Vol. 2012, Article ID 248989, 2012

[18] Y. Lim, K. Lee, S. Moon, "Effects of a Post-Weld Heat Treatment on the Mechanical Properties and Microstructure of a Friction-Stir-Welded Beryllium-Copper Alloy”, Metals-Open Access Metallurgy Journal, Vol. 9, No. 4, Article ID 461, 2019

[19] M. Hariram, D. Theerath, P. Chakravarthy, R. A. Kumar, "Influence of cold work on aging response of C17200-beryllium copper alloy C17200", Materials Today: Proceedings, Vol. 4, No. 10, pp. 11188 11193,2017 